\title{
REMOTE SENSING TECHNOLOGIES AND GEOSPATIAL MODELLING HIERARCHY FOR SMART CITY SUPPORT
}

\author{
M. Popov, O. Fedorovsky, S. Stankevich, V. Filipovich, A. Khyzhniak, I. Piestova, M. Lubskyi, M. Svideniuk \\ Scientific Centre for Aerospace Research of the Earth, NAS of Ukraine \\ Oles Gonchar str., 55-B, Kiev, Ukraine - tel./fax: +38 (044) 48201 66, e-mail: mpopov@ casre.kiev.ua
}

\begin{abstract}
KEY WORDS: Smart city, Decision-making support, Remote sensing technology, Geospatial modelling, City development forecasting
\end{abstract}

\author{
Commission V, WG V/7
}

\begin{abstract}
:
The approach to implementing the remote sensing technologies and geospatial modelling for smart city support is presented. The hierarchical structure and basic components of the smart city information support subsystem are considered. Some of the already available useful practical developments are described. These include city land use planning, urban vegetation analysis, thermal condition forecasting, geohazard detection, flooding risk assessment. Remote sensing data fusion approach for comprehensive geospatial analysis is discussed. Long-term city development forecasting by Forrester - Graham system dynamics model is provided over Kiev urban area.
\end{abstract}

\section{INTRODUCTION}

The development of the world economy and industry is unambiguously accompanied by the concentration of forms and types of human activity, which leads to an increase in the population in urban settlements. Over the past 20 years, the number of urban dwellers in the world has doubled, and especially large urban settlements are developing and developing rapidly. Maintaining comfortable conditions for people's lives in large urban settlements is a very difficult task, and its solution is the concept of a smart city, developed in recent years (Albino, Berardi and Dangelico, 2013). The smart city concept to be a key solution to challenges brought by a fast growing urbanization such as urban sprawl, environmental challenges, transportation, high costs of management, energy constraints, citizens' quality of life, etc (Zygiaris, 2013).

The realization of the smart city the concept is associated with the receipt and processing of large amounts of information on traffic flows, population, municipal structures, the state of vegetation and the atmosphere, etc. An important source of such information is the data delivered by aerial and space surveying. The processing of these data, the development of quantitative and spatial (graphic) models, necessary for the operative analysis of situations and managerial decisions making by the city authorities, is carried out with the help of geoinformation systems (GIS).

The goal of this paper is to demonstrate how modern remote sensing technologies and geospatial modelling can be used for smart city support. The paper proposes a multi-level scheme for obtaining and preparing information for making management decisions, which includes means of obtaining satellite and airborne iconic data, thematic analysis of this data (2), geospatial analysis based on data fusion (3), and geoinformation modelling (4).

A set of indicators of the state of urban vegetation that can be obtained from multispectral satellite information is substantiated.

Investigating the territory of Kiev city as a case it is shown how using infrared remote sensing technology one can estimate the temperatures of urban surfaces, including temperature distribution on city's districts, and forecast possible temperature changes. This is especially important, because the specialists say about the objective dependence of people health on climatic conditions, temperature of surrounding environment, etc.

A planning the development of urban infrastructure (buildings, transport arteries, wire communications and so on), their sustainable operation is impossible without the stability of the state of near-surface soil horizons, maintaining the natural water balance. The paper deals with the possibilities of radar interferometry for monitoring the state of the relief of urban areas and identifying dangerous phenomena.

It is shown that there is a real possibility to predict the development of flooding/underflooding sites in urban area by the analysis of spatio-temporal series of satellite imagery in thermal infrared band and digital terrain elevation data.

The final part of the paper is devoted to the application of the methods of comprehensive modelling of long-term city development for forecasting and decision-making.

\section{REMOTE SENSING TECHNOLOGIES FOR SMART CITY INFORMATION SUPPORT}

As an important part of the urban area monitoring subsystem, remote sensing can deliver geospatial data in different fields of expertise quickly and relatively inexpensive. Various types of imaging systems are capable to acquire necessary remote data for one or more applications. This is possible to understand the four-level remote monitoring data flow hierarchy for the smart city, as shown in Figure 1 diagram.

At the first level of hierarchy the various types of satellite and airborne remote data sources are situated: multispectral, infrared, radar and others. The second level includes various remote monitoring applications: land use, vegetation, thermal condition, hazards, etc. At the third level, the data fusion and geospatial analysis are performed. The fourth level is comprehensive modeling and forecasting for decision-making support. 


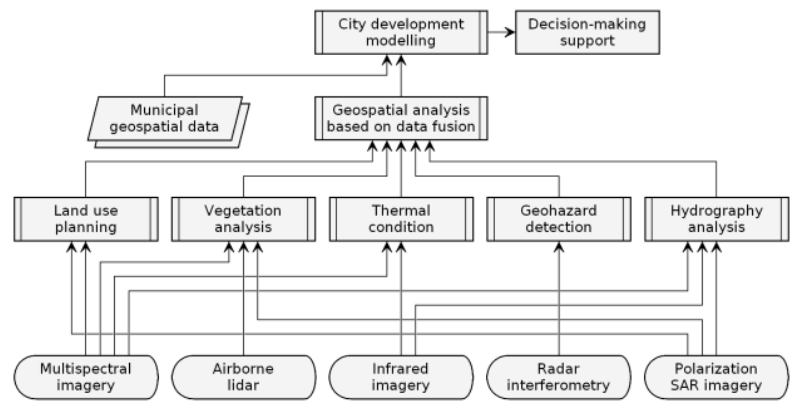

Figure 1 . Smart city remote monitoring flowchart

Let's consider all this in more detail below.

\subsection{Multispectral remote sensing for urban vegetation analysis}

To improve the quality of urban life, the continuous operational monitoring and forecasting of urban area vegetation condition is required. Special attention should be paid to estimate the vegetation condition using modern remote and field data and GIS technologies. The basic requirements for the multispectral aerospace imagery and justifies the necessary operations for data preprocessing are formulated. The mandatory groundbased measurements must be performed according to special procedure and was carried out in statistically significant amount.

Main indicators of vegetation condition in urban area are substantiated, that can be extracted from multispectral imagery. For the vegetation amount, the leaf area index (LAI) is intended, which is an important phytometric estimator of the vegetation spatial distribution. The method for the vegetation amount estimation based on robust nonlinear regression between LAI and NDVI vegetation index was developed. The main types of regressions between LAI and NDVI were considered and algorithms for ones' restoration were developed. The algorithm for regression approximation by optimal spline interpolation is provided the best accuracy (Piestova, 2015).

For the vegetation quality the extremum value of spectral reflectance derivative in the red-edge band $0.68-0.73 \mu \mathrm{m}$ - rededge tangent (RET) is used as quantitative estimator, directly related to the chlorophyll and other vital-making enzymes in photosynthetically active green plants. The method for the vegetation quality assessment using RET is developed. The regression between RET and expert-determined normalized vegetation quality factor (VQF) on reference sites is restored (Figure 2, (Stankevich et al., 2015)). An approach to classification for studying the state of plant communities at different phases of the phenological cycle is considered (Stankevich, Piestova and Podorvan, 2016).
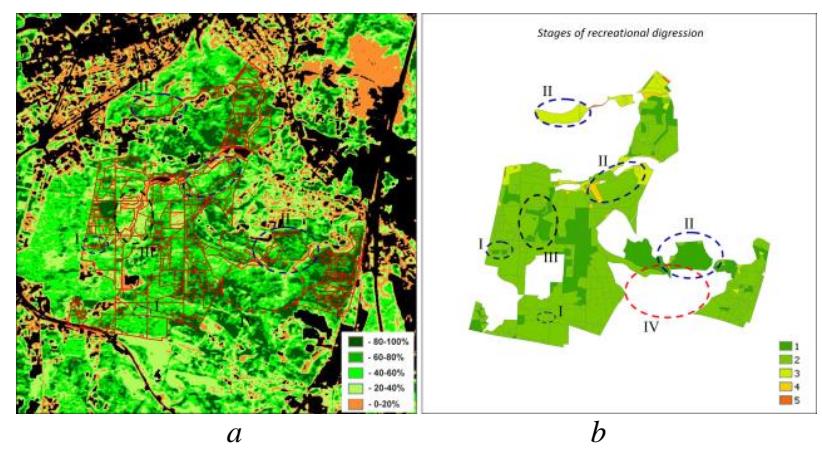

Figure 2. Vegetation quality distribution map by satellite data
(Sich-2/MSU, September 1, 2011, $8 \mathrm{~m}$ spatial resolution) and in-situ inspections (Golosiivsky National Nature Park, Kiev, Ukraine)

The main indicators for long-term spatial and temporal changes in vegetation condition are specified. First one is the linear trend, which is described by the mean value over the whole period of analysis and average annual increment. Second one is the periodic component, which recognizes the seasonal variations in vegetation condition/

\subsection{Infrared remote sensing for thermal condition forecasting in urban area}

In conditions of climate change, urban areas suffer the most heat load, which negatively affects the human health. Therefore it is necessary to determine the most dangerous areas of the city in terms of heat pollution, to forecast the changes' trends and dynamics in surface temperatures and to take measures to ensure the population safety. One of the methods for obtaining information about city "heat island" condition is the satellite monitoring of urban areas in the visible and, especially, in the long-wave infrared spectrum.

On the basis of the satellite data time series analysis in the visible and infrared bands during the study of urban "heat islands", areas of maximum and minimum of Kiev urban environment surface temperature increase over the past 30 years were identified (Figure 3). The urban environment's surface temperature time series were constructed, temperature trends were extracted, and the forecast of the expected average and maximum temperatures for the next 10 years was calculated for the case if the current trend of climate warming will still (Figure 4). It is shown that the surface's temperature increase together with increasing of building density destruction of green spaces, and stabilization and reduction of heat load occurs in areas with forest park and water objects. As a result of the urban area's temperature monitoring, the zoning of the Kiev area according to the degree of thermal load is conducted and recommendations for the reduction of global warming's negative impact on the population's life safety are made.
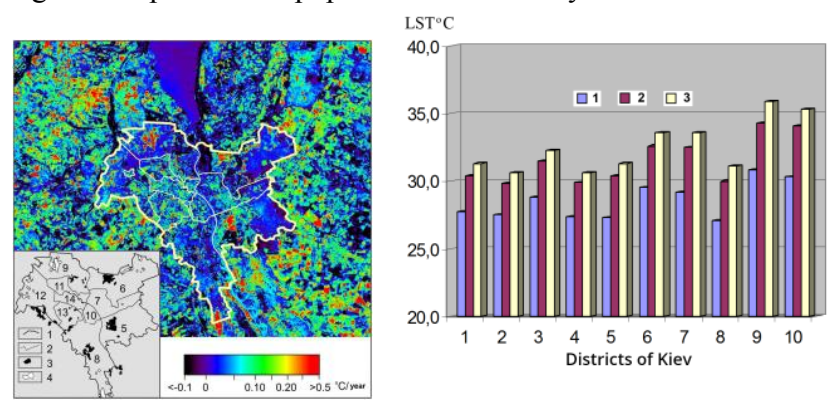

Legend: 1 - Kiev city border, Legend: 1 - average land surface 2 - districts' borders, 3 - temperature for July-August plots of current construction, 1995, 2 - average land surface 4 -forest cutting sites temperature for July-August 2014, 3 - expected average land surface temperature for JulyAugust 2024

Figure 3. The average annual Figure 4. The average daily land temperature increment $\left({ }^{\circ} \mathrm{C}\right) \quad$ surface temperature forecast in within the Kiev and suburban Kiev for July-August 2024 area in July-August for the period, based on Landsat 1985-2015 period infrared imagery time series analysis 
In general, the forecast shows that in Kiev, till 2024 the average land surface temperature in July-August will increase up to $+31,6^{\circ} \mathrm{C}$, the average temperature over the hottest days will increase up to $+41,6^{\circ} \mathrm{C}$ and additional heating of the surface of some sites up to $+51,0^{\circ} \mathrm{C}$. The most comfortable districts for living are with significant forest park areas (Desnianskyi, Holosiivskyi) where the average temperature of the land surfaces in summer will not exceed $+31^{\circ} \mathrm{C}$. The most problematic in terms of human health are areas with buildings density (Shevchenkivskyi, Solomianskyi), where average summer temperature of land surface is expected to be higher than $+35^{\circ} \mathrm{C}$ (Gornyy et al., 2016).

\subsection{Radar interferometry for geohazard detection in urban} area

Synthetic Aperture Radar (SAR) data, since the launch of Sentinel-1 by European Commission and European Space Agency (ESA) C-band SAR satellite system, are very important for remote sensing applications, including smart city support (Geudtner et al., 2014). Synthetic Aperture Radar Interferometry (InSAR) imaging mode provides the capability to monitor precise surface displacements. This process is based on data time series for long-term continuity of observations with equidistant and short time intervals (interferogram stacks) (Yuan et al., 2017).

In our research the land surface displacements are mapped using two pairs of Sentinel-1A InSAR data over the Kropivnitsky city (Figure $5 a$ ), where mining activities are present. Radar images are acquired 12/24 September 2015 and 6/18 October 2017. Co-registered InSAR image pairs was used for interferogram computing and coherence estimating (Figure $5 b$ ). Goldstein phase filtering was applied (Goldstein and Werner, 1998) to reduce the noise and to enhance the phase unwrapping accuracy (Chen and Zebker, 2002). Finally, the unwrapped InSAR interferometric phase was converted into digital elevation map.

As a result, we have obtained two terrain elevation sets for September 2015 and October 2017 to map elevation displacements in a two-year period (Figure $5 c$ ).

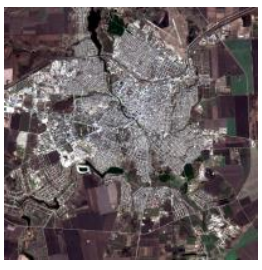

$a$

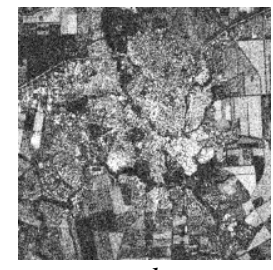

b

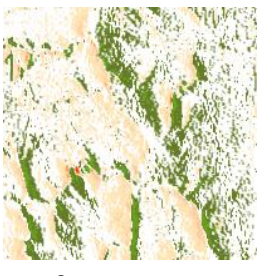

c
Legend: - unclassified (no data), - very strong down $(<-$ $0.6 \mathrm{~m})$, - strong down $(-0.6 . .-0.3 \mathrm{~m}), \quad-$ moderate down $(-$ $0.3 \ldots-0.15 \mathrm{~m})$, - weak down $(-0.15 \ldots-0.05 \mathrm{~m})$, \% - no

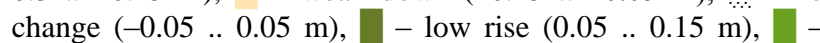
medium rise $(0.15 \ldots 0.3 \mathrm{~m})$, - high rise $(0.3 \quad . .0 .6 \mathrm{~m})$, very high rise $(>0.6 \mathrm{~m})$

Figure 5. Kropivnitsky city (Ukraine) radar interferometry mapping: $a$-Sentinel-2A multispectral image (March 31, 2017 ,

$10 \mathrm{~m}$ spatial resolution), $b$ - Sentinel-1A InSAR coherence map, $c$ - terrain elevation displacements map (from September 2015 till October 2017)

InSAR imaging must be performed many times over area of interest for permanent monitoring. Such technique is a useful and versatile tool for analysis of geological emergency hazard (Stankevich, Piestova and Titarenko, 2017). Radar interferometry is potentially capable to detect not only the catastrophic sinkholes of land surface, but also their precursors. 2.4 Land use change mapping by remote sensing data in urban planning

Satellite monitoring of urban areas for urban planning is based on spatial-temporal landscape change detection and city functional structure analysis. As example, a comparative analysis of the Landsat-5/TM (06.06.1985) Sich-2 (10.10.2011) satellite data was performed over southwestern part of the Kyiv city (Figure 6).

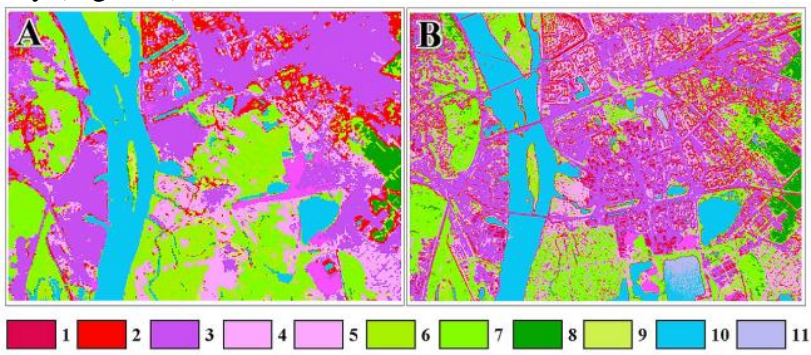

Legend: 1 - continuous urban zone, 2 - discontinuous urban zone, 3 - industrial and transportation facilities, 4 - construction sites, 5 - urban green belts, 6 - transitional tree and shrub vegetation, 7 - deciduous forest and urban gardens, 8 coniferous forest, 9 - herbaceous vegetation and natural grasslands, 10 - open water bodies, 11 - marshed ponds

Figure 6. Landscape and functional structure changes within the southeastern part of the Kyiv city by multispectral satellite imagery interpretation: $a$ - Landsat-5/TM (06.06.1985), $b-$ Sich-2 (10.10.2011)

During this more than 25 years period, the maximum changes were within urban industrial zones including transportation network (increased by 28 times), green area (decreased by $10 \%$ ), the total area of ponds (increased by $18 \%$ ), and area of urban development (increased by $44 \%$ ). Area of coniferous forests reduced, especially in the southwestern part of Kyiv and in the surrounding suburban area. There are similar changes inside the Dnieper River valley in the southern part of Kyiv city (Filipovich, Mychak and Krylova, 2014).

\subsection{Hydrography geospatial analysis for flooding hazard detection in urban area}

It is possible to predict the development of flooding/underflooding sites in urban area by the analysis of spatio-temporal series of satellite imagery in thermal infrared band and digital terrain elevation data. For example, one of the hazardous site in the Kiev city is Obolon area (Figure 7).

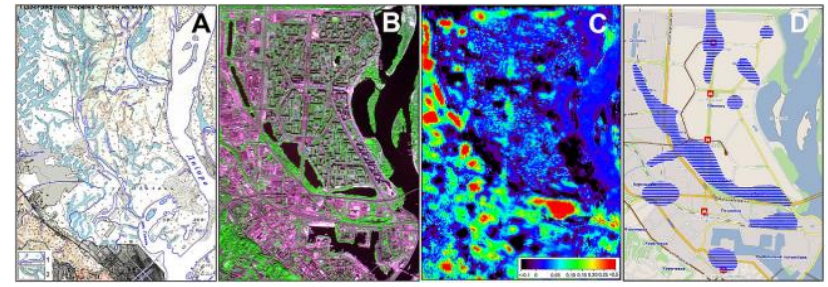

Legend: 1 - rivers, streams and lakes, 2 - swamps

Figure 7. Remote sensing and hydrogeological data analysis for the flood zones prediction: $a$ - historical hydrographical network, 1897; $b$-Sich-2/MSU satellite image of study area, $05.10 .2012 ; c-$ land surface temperature increment by thermal remote sensing time series analysis (from 1985 till 2014); $d-$ 


\section{flooding hazard final map}

The main ecological problems of the Obolon site are flooding with groundwater and subsidence of the soils (Filipovich, 2015). The minimum gradients of the average land surface temperature increment were mapped for the 1985-2014 period (Figure $7 c$ ) at this site using thermal infrared satellite imagery (Teremenko, Mychak and Filipovich, 2011). Map of study area shows that the natural soil cover replacement with construction and road pavements practically excluded evaporation from the land surface and disturbs the water balance. Joint analysis of these data with a groundwater levels displays the isolated drowning cells as most potentially hazardous plots (Figure $7 d$ ). Here it's necessary to strengthen underground communications, basements and foundations of dwelling houses.

\section{HIGH-LEVEL GEOSPATIAL ANALYSIS BASED ON DATA FUSION FOR SMART CITY SUPPORT}

The data fusion aim is a joint analysis of all available geospatial data over specific territory - remote, field, previously accumulated, thematic and so on (Stankevich and Titarenko, 2014). The preparatory procedures that ensures joint geo-spatial analysis - formats conversion, spatial extents and datums arrangement, spatial regularization, methods determining for data of different physical domains processing - and true semantic-oriented procedures to obtain final results should be distinguished (Flowerdew, 1991).

Modern geoinformation technologies provide a powerful methods for spatial matching of regular and irregular raster and vector georeferenced data - from simple spline interpolation to physical simulation (Giuliani et al., 2012). Obviously, the quantitative data fields of different physical domains should be converted into a common measurable form before processing, for example, by various kinds of scaling, normalization or filtering (Ding and Meng, 2014).

Now the purpose-oriented data fusion can be performed in a variety of ways such as visual analysis using special multidimensional visualization (Steed et al., 2013), geospatial and topological ontologies development (Du et al., 2011), applying geostatistical models, classifiers and anomaly detectors (Shekhar et al., 2011) and other. Advantages of mentioned methods are objectivity, logic consistency, easy algorithmization, wide possibilities of re-analysis. In particular, we have already proposed and implemented several approaches to remote and geophysical data fusion, which are based on similar models (Popov et al., 2015; Popov et al., 2017).

Data fusion and geospatial analysis can be put in practice as object-oriented middleware, augmented by rule-based inference expert system for smart city support.

\section{COMPREHENSIVE MODELLING OF LONG-TERM CITY DEVELOPMENT FOR FORECASTING AND DECISION-MAKING}

The proposed method for the comprehensive modeling of the city environment is based on the system dynamics theory by $\mathrm{D}$. Forrester and uses the hierarchy and causal relations between modules of a complex system (Forrester, 1971). The essence of the above method is to create a conceptual model and formalize mathematical equations which describe influences balance of the system (Alfeld and Graham, 1976). There are four types of problems to be resolved: information analysis and comprehension, forecasting and planning. The problem of the information comprehension allows us to evaluate model parameters and to restore spatial and temporal structure of the urban landscapes using observation data. The problem of forecasting has standard definition and implementation: the state function which characterizes the behavior of the system in space and time is calculated with the given input parameters of the model. The scenarios simulation of the urban agglomerations sustainable development is performed for the given socio-economic criteria, health standards of the environment and other constraints.

The basis for model creation is the equation of the system dynamics, which in general terms can be defined as

$$
\frac{d \mathbf{x}(t)}{d t}=F(\mathbf{x}(t), \mathbf{p}(t), t) \rightarrow \mathbf{x}\left(t_{0}\right)=\mathbf{x}_{0}
$$

where $\mathbf{x}(t)$ is vector-function of the state variables, $\mathbf{p}(t)$ is vector-function of the system's parameters, $F(\mathbf{x}(t), \mathbf{p}(t), t)$ is nonlinear, in the general case, non-stationary vector-function, which in the vast majority of cases represents the difference between tempos (flows, velocities) of the positive and negative feedbacks:

$$
F(\mathbf{x}(t), \mathbf{p}(t), t)=f^{+}(\mathbf{x}(t), \mathbf{p}(t), t)-f(\mathbf{x}(t), \mathbf{p}(t), t)
$$

where $f^{+}(\mathbf{x}(t), \mathbf{p}(t), t)$ is the speed of the positive feedback, which includes all factors that cause the growth of a variable $\mathbf{x}$, $f(\mathbf{x}(t), \mathbf{p}(t), t)$ is the speed of the negative feedback, which includes all the factors causing the fall of the variable $\mathbf{x}$.

Verification of the model was conducted using the information about the environmental condition of the city of Kyiv. The urban landscape components dynamic was recreated using the above model and was compared with dynamic of the same variable characteristics taken from the General Plan of Kyiv and statistical reports (Sokolovska, Nikitenko and Fedorovskiy, 2014).

Computational experiments, which were carried out on the city system dynamics model by Forrester - Graham, showed the possibility to use basic model for assessment of individual city area components state with the data of terrestrial observations. Modification of the urban model was carried out by introducing models based of equations for environment state integral assessment function (accordance function) and remotely sensed data assimilation for urban landscape components structure changes dynamics research and forecast up to 2025 (Sokolovska, 2013).

The model and appropriate connected subsystems (modules) were formed and system borders and detail level were defined based on the modified system dynamics simulation model of urban development including urban landscape components and some socio-ecological factors such as: residential areas, roads, wastelands and areas under construction, the number of industrial and commercial enterprises, greenhouse gas emissions, water surface area, building density, population, etc. (Figure 8).

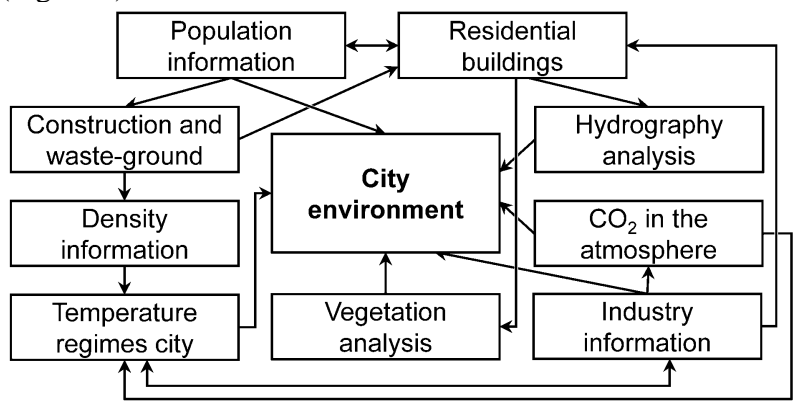

Figure 8 . The diagram of the interconnections between modules 
of the modified model

The causal relationships between modules were obtained using statistical, analytical and expert information and appropriate charts were built. The result of simulation and prediction of environmental conditions in Kiev up to 2025 is shown on Figure $9 a$.

The plot shows how model adequately reacts on the change of the urban area components values. With the vegetation area increasing also improves environmental condition within the Kiev city area, but the growth of the anthropogenic impact leads to degradation of the environmental condition. Increase in building's area and water surface area doesn't cause valuable impact on the environmental condition of urban area. Forecasting assessment of environmental condition is shown for the gradual change of urban landscape: vegetation and anthropogenic impact $-\mathrm{CO}_{2}$ by $10 \%$ from nominal value of the year 2016.

The accuracy of the forecasting for the selected model was assessed calculating the correlation index $(R)$ of the data obtained in the past on land statistics and the data obtained during the simulation for the 1994-2016 period (Figure 9b). $R$ is equal 0.86 which is enough for practical use of the environmental monitoring of urban area.
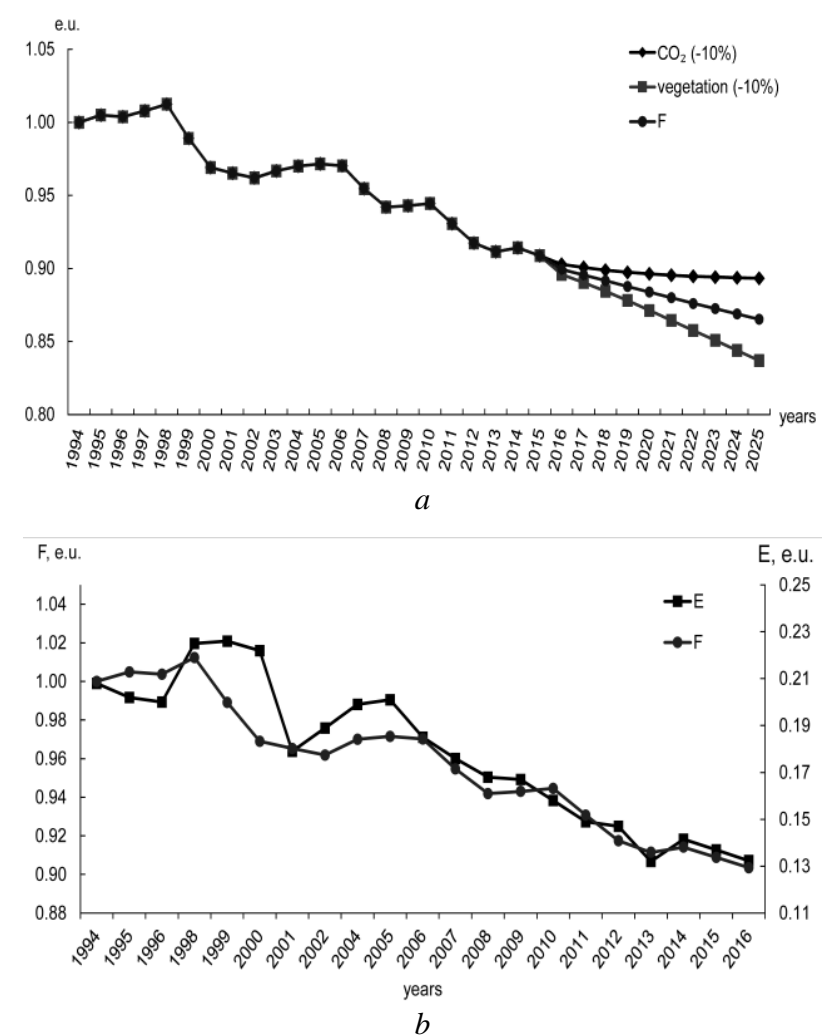

Figure 9. Modelling results: $a-$ Kiev city environment condition (accordance function) up to 2025 in case of reducing the vegetation area on $10 \%$ relatively to $2016 ; b$ - prediction accuracy on used model

\section{CONCLUSIONS}

So, our research shows the wide possibilities and prospects of using modern remote sensing technologies and geoinformation modelling for smart city support.

A multi-level scheme is proposed for obtaining and preparing information for making management decisions, which includes means for obtaining satellite and airborne iconic data, thematic analysis of this data, geospatial analysis based on data fusion, and geospatial modelling.

The experimental studies outcomes confirm the efficiency and practicability of proposed approach. The outlined comprehensive monitoring subsystem for smart city support is flexible and extensible. New remote and modelling elements can be integrated into it easily at each level of hierarchy. The subsystem itself can be connected to existing control, public notification and information disseminating subsystems (Stankevich et al., 2015).

Further research should be aimed at development of information services for on-line processing of large arrays of incoming data (big data) and for operational analysis of information for subsequent decision-making by city authorities, as well as information sharing for other users and publics

\section{REFERENCES}

Albino, V., Berardi, U., Dangelico, R.M., 2013. Smart cities: definitions, dimensions, and performance. Proceedings of $8^{\text {th }}$ International Forum on Knowledge Asset Dynamics (IFKAD 2013) "Smart Growth: Organizations, Cities and Communities" / G. Schiuma, J.C. Spender, A. Pulic (Eds), Zagreb: University of Zagreb, pp. 1723-1738.

Alfeld, L.E., Graham, A.K., 1976. Introduction to Urban Dynamics. Waltham: Pegasus Communications, 300 p.

Chen, C.W., Zebker, H.A., 2002. Phase unwrapping for large SAR interferograms: Statistical segmentation and generalized network models. IEEE Transactions on Geoscience and Remote Sensing, Vol.40, No.8, pp. 1709-1719.

Ding, L., Meng, L., 2014. A comparative study of thematic mapping and scientific visualization. Annals of GIS, Vol.20, No.1, pp. 23-37.

Du, H., Jiang, W., Anand, S., Morley, J., Hart, G., Jackson, M.J., 2011.Ontology-based approach for geospatial data integration. Proceedings of the 25th International Cartographic Conference (ICC 2011), Paris: International Cartographic Association, pp. 119-128.

Filipovich V., Mychak A., Krylova A., 2014. Use satellite data in monitoring ecological condition of urban landscape. Proceedings of $14^{\text {th }}$ International Multidisciplinary Scientific Conference on Informatics, Geoinformatics and Remote Sensing (SGEM 2014), Albena, Bulgarian Academy of Sciences, Vol. III, pp. 1061-1068.

Filipovich, V.E., 2015. Use of space information for forecasting the development of dangerous geological processes (underflooding and flooding) in the case of individual districts Kyiv (Ukrainian). Ukrainian Journal of Remote Sensing, No.7, pp. 58-63.

Flowerdew, R., 1991. Spatial data integration. Geographic Information Systems: Principles and Applications / D.J. Maguire, M.F. Goodchild, D.W. Rhind (Eds), London: Longman, pp. 375-387.

Forrester, J.W., 1971. Counterintuitive behavior of social systems. Technology Review, Vol.73, No.3, pp. 52-68.

Geudtner, D., Torres, R., Snoeij, P., Davidson, M., Rommen, B., 2015. Sentinel-1 system capabilities and applications. 
Proceedings of International Geoscience and Remote Sensing Symposium (IGARSS 2014), Quebec: IEEE, pp. 1457-1460.

Giuliani, G., Nativi, S., Lehmann, A., Ray, N., 2012. WPS mediation: An approach to process geospatial data on different computing backends. Computers \& Geosciences, Vol.47, No.10, pp. 20-33

Goldstein, R.M., Werner, C.L., 1998. Radar interferogram filtering for geophysical applications. Geophysical Research Letters, Vol.25, No.21, pp. 4035-4038.

Gornyy, V.I., Lyalko, V.I., Kritsuk, S.G., Latypov, I.Sh., Tronin, A.A, Filippovich, V.E., Stankevich, S.A., Brovkina, O.V., Kiselev, A.V., Davidan, T.A., Lubskii, N.S., Krylova, A.B., 2016. Forecast of Saint-Petersburg and Kiev thermal replies on climate change (on the basis of EOS and Landsat satellite imagery). Current Problems in Remote Sensing of the Earth from Space, Vol.13, No.2, pp.176-191.

Piestova, I., 2015. Quantitative vegetation mapping of urban area using high-resolution multispectral satellite imagery. Science-Based Technologies, Vol.2, No.26, pp. 153-158.

Popov M.O., Stankevich, S.A., Topolnitsky, M.V., Titarenko, O.V., 2017. Integration of remote and geological/geophysical data for oil and gas onshore deposits prospecting. Environmental Safety and Natural Resource Management, Vol.23, No.1-2, pp. 36-43.

Popov, M.A., Stankevich, S.A., Topolnitsky, M.V., Sedlerova, O.V., 2015. An approach to integrating the remotely sensed, geological, and geophysical data using the Dempster-Shafer mathematical theory. Reports of the National Academy of Sciences of Ukraine, No.4, pp. 94-98.

Shekhar, S., Evans, M.R., Kang, J.M., Mohan, P., 2011. Identifying patterns in spatial information: A survey of methods. Wiley Interdisciplinary Reviews: Data Mining and Knowledge Discovery, Vol.1, No.3, pp. 193-214.

Sokolovska, A.V., 2013. Space monitoring of ecological condition of urban territories (the Kyiv city is used as an example). Space Science and Technology, Vol.19, No.4, pp. 4449.

Sokolovska, A.V., Nikitenko, O.V., Fedorovskiy, O.D., 2014. System modeling and forecast of environmental conditions of Kyiv based on statistical data of space monitoring and groundbased observations. System Research \& Information Technologies, No.4, pp. 12-21.

Stankevich, S., Dudar, T., Kozlova, A., Eidelstein, L., 2015. Remote sensing as information tool for engaging the public to counteract terrorism and disasters. Engaging the Public to Fight the Consequences of Terrorism and Disasters. I. Apostol, J. Mamasakhlisi, D. Subotta, D.W.G. Reimer (Eds), Amsterdam: IOS Press, pp. 91-103.

Stankevich, S.A., O.V. Titarenko., 2014. Remote sensing and geological/geophysical data integration for oil and gas prospecting. Journal of Georgian Geophysical Society.mIssue (A). Physics of Solid Earth, Vol.17a, pp. 152-157.

Stankevich, S.A., Piestova, I.A., Godyna, O.O., Filozof, R.S., 2015. Vegetation quality remote assessment in urban area: Golosiivsky NNP case study (Ukrainian). Scientific reports $\begin{array}{lrrrr}\begin{array}{l}\text { NULES of } \\ \text { http://nd.nubip.edu.ua/2015 }\end{array} & \text { 2/5.pdf. } & \text { Vol.51, } & \text { No.2 }\end{array}$

Stankevich, S.A., Piestova, I.A., Podorvan, V.N., 2016. Deep learning concept for hyperspectral imagery classification. Central European Researchers Journal, Vol.2, No.1, pp. 30-36.

Stankevich, S.A., Piestova, I.A., Titarenko, O.V., 2017. Geological emergency assessment using satellite radar interferometry: Krivoy Rog urban area case study. TIEMS Newsletter Special Edition, No.5, pp. 21-24.

Steed, C.A., Ricciuto, D.M., Shipman, G., Smith, B., Thornton, P.E., Wang, D., Shi, X., Williams, D.N., 2013. Big data visual analytics for exploratory Earth system simulation analysis. Computers \& Geosciences, Vol.61, No.12, pp. 71-82.

Teremenko, O.M., Mychak, A.G., Filipovich, V.E., 2011. Monitoring of the urbanized territory drainage and the forecast of dangerous natural process location based on GIS/remote sensing technologies (Russian). Proceedings of Irkutsk State Technical University, Vol.55, No.8, pp. 54-59.

Yuan, W., Wang, Q., Fan, J., Li, H., 2017. Mining land subsidence monitoring using Sentinel-1 SAR data. The International Archives of the Photogrammetry, Remote Sensing and Spatial Information Sciences, Vol.XLII, No.2/W7, pp. 655658 .

Zygiaris, S., 2013. Smart city reference model: Assisting planners to conceptualize the building of smart city innovation ecosystems. Journal of the Knowledge Economy, Vol.4, No.2, pp. 217-231. 